\title{
Parental goals and talk with toddlers
}

\section{Citation}

Rowe, Meredith L., and Allison Casillas. 2010. "Parental Goals and Talk with Toddlers." Infant and Child Development 20 (5) (October 6): 475-494.

\section{Published Version}

doi:10.1002/icd.709

\section{Permanent link}

http://nrs.harvard.edu/urn-3:HUL.InstRepos:13041205

\section{Terms of Use}

This article was downloaded from Harvard University's DASH repository, and is made available under the terms and conditions applicable to Other Posted Material, as set forth at http:// nrs.harvard.edu/urn-3:HUL.InstRepos:dash.current.terms-of-use\#LAA

\section{Share Your Story}

The Harvard community has made this article openly available.

Please share how this access benefits you. Submit a story.

Accessibility 


\title{
Parental Goals and Talk with Toddlers
}

\author{
Meredith L. Rowe ${ }^{a, b, *}$ and Allison Casillas ${ }^{b}$ \\ aniversity of Maryland, College Park, MD, USA \\ ${ }^{\mathrm{b}}$ University of Chicago, IL, USA
}

Myriad studies support a relation between parental beliefs and behaviours. This study adds to the literature by focusing on the specific relationship between parental goals and their communication with toddlers. Do parents with different goals talk about different topics with their children? Parents' goals for their 30-month olds were gathered using semi-structured interviews with 47 primary caregivers, whereas the topics of conversations that took place during interactions were investigated via coding videotapes of observations in the home. Parents' short- and long-term goals spanned several areas, including educational, social-emotional, developmental and pragmatic goals. Parental utterances most frequently focused on pragmatic issues, followed by play and academic topics. Parents who mentioned long-term educational goals devoted more of their talk to academic topics and less to pragmatic topics, controlling for socioeconomic status. Thus, parental goals differ and these differences relate to the conversations parents engage in with their children. Copyright (C) 2010 John Wiley \& Sons, Ltd.

Key words: parental beliefs; parental goals; parent-child interaction; parental talk

Parents influence multiple aspects of their child's development. While theories differ as to the specific role of the parent in child development, it is clear that understanding parents' beliefs about childrearing and their behaviours as parents provide insight into the mechanisms through which parents exert their influence upon children. In this study we address this larger issue by investigating the relation between parental goals and communication with children. Our specific interests focus on what parents talk about with their toddlers and whether or not their chosen topics of conversation relate to certain underlying goals (short term or long term) they hold for their children.

\section{Parental Beliefs and Behaviours}

Parental beliefs are the framework that shapes parent-child interactions, and these systems lay the groundwork for all experiences the parent and child share

\footnotetext{
*Correspondence to: Meredith L. Rowe, Department of Human Development, 3304T Benjamin Building, University of Maryland, College Park, MD 20742, USA. E-mail: mrowe@umd.edu
} 
together (Jimerson \& Bond, 2001; McGillicuddy-De Lisi \& Sigel, 1995). Parents' beliefs, consisting of ideas, knowledge, cognitions, values, goals, and attitudes pertaining to parent-child relationships, serve multiple functions (Bornstein \& Cheah, 2006). Empirical studies show that parents' beliefs about child development have significant direct and indirect effects on children's cognitive, emotional, and social competence (Sigel \& McGillicuddy-De Lisi, 2002). Not only do parental beliefs affect the developmental outcomes of children (Grusec, Rudy, \& Martini, 1997; Harkness \& Super, 1996), but they also influence parental behaviours, mediate the effectiveness of parenting practices, and assist in organizing parenting (Chao, 1996; Darling \& Steinberg, 1993; Maccoby \& Martin, 1983; Teti \& Candelaria, 2002). Parental belief systems are the nexus through which behaviour is interpreted and organized, and thereby affect the mutual regulation between the parent and child (Jimerson \& Bond, 2001; Pomerleau, Malcuit, \& Sabatier, 1991). Parents' beliefs and values are reflected in the ways in which they care for and rear their children (Luster \& Okagaki, 1993), and thus serve as a fundamental foundation to the parent-child relationship.

While empirical evidence demonstrates that beliefs are associated with behaviour, and that behaviour, in turn, is related to child outcomes (Benasich \& Brooks-Gunn, 1996; Bornstein \& Cheah, 2006; Miller, 1988), some studies fail to find strong correlations. As Sigel asserted, 'the success rate for uncovering robust findings between stated beliefs and overt actions has been disappointing' (1992; p. 433). A number of studies reveal moderate to weak belief-behaviour relationships, while some show no correlation (e.g. Cote \& Bornstein, 2000; McGillicuddy-De Lisi, 1992). However, Sigel (1992) acknowledged the reason some studies were unable to establish linkages between parental beliefs and behaviours was rooted in methodological limitations (e.g. interview techniques). Ultimately, the study of the belief-behaviour connection is complex, as very few studies have directly investigated the relationship. Despite the strength of associations between parental beliefs and behaviours, even modest results suggest that beliefs are in fact sources of influences on parent behaviour (Sigel, 1992).

\section{Role of Culture}

Much of the research on parents' beliefs and behaviours has been cross-cultural, showing relations between parental beliefs pertaining to the socio-affective and cognitive domains in child development and parent-child interactions (e.g. Harkness \& Super, 1996). That is, culturally distinct maternal beliefs and values are correlated with culturally specific maternal behaviours across multiple cultures (e.g. Gaskins, 1996; Pomerleau et al., 1991). Although parenthood is universal across cultures, child-rearing patterns and values are not uniform (LeVine, 1974). For example, in regard to parental talk, Schieffelin (1990) and Ochs (1988) found that infant-directed talk is virtually absent for the Kaluli of Papua New Guinea and the Samoans of Polynesia, who do not consider infants as communicative partners. However, in countries such as the United States, Kenya, Mexico, and in Western Europe, parent-child conversations are common because parents from these cultures hold the belief that infants are capable of understanding and participating in verbal interactions (LeVine, Miller, Richman, \& LeVine, 1996). Further, Johnston and Wong (2002) identified noticeable differences between Western and Chinese cultures in child-rearing beliefs and values in relation to culturally distinct patterns of child directed talk. Specifically, Chinese parents were less likely to report that they prompted their children for personal narratives, talked with their children about non-shared 
events throughout the day, or permitted their children to engage in conversation with adults who are not family members. Moreover, Chinese parents more often reported using picture books and flash cards to teach their children new words, as they agreed more strongly that children learn best with instruction, compared with learning during play. The researchers concluded that Chinese parents feel they need to be an active participant in teaching their children, both for moral and social reasons (Johnston \& Wong, 2002). Thus, parental beliefs serve to define culture and the transmission of cultural information passed on throughout generations (Bornstein \& Cheah, 2006). One way to capture this transmission of cultural information is through communication, as parents' ideologies of childrearing are closely linked to the ways they think children should be spoken to (Lieven \& Stoll, 2010).

\section{Goals}

Conceptualized as consisting of not only child-rearing values (Wang \& TamisLeMonda, 2003) and of parent-child interactions (Keller et al., 2003), parents' cultural belief systems also encompass child-rearing goals and the goals of human development (Rogoff, 2003; Williams \& Ispa, 1999). Like parental beliefs, parenting goals represent cultural norms and values developed by a particular group in a society that function to provide optimal regulation of their social life (Goodnow, 2002). LeVine suggests that a common set of goals exists universally among all cultures and that there is a natural, hierarchical sequence for these goals. Physical survival and health maintains the highest priority, preceding economic selfmaintenance and the final universal goal of maximization of cultural values (e.g. morality, religious piety, wealth, intellectual achievement, etc.) (LeVine, 1974,1980). Within the sequence, each goal remains a prerequisite for the subsequent one, and parents ascend the hierarchy as each lower-level goal is satisfied (Goodnow \& Collins; 1990). Each culture shapes these goals to adapt to the hazards unique to each environment, and to maximize the quality of life, which results in a set of customs for parenthood. Therefore, goals can differ substantially according to the cultural standards of human behaviour, parental investment strategies, and the natural and institutional environments of each society (LeVine, 1980). For instance, in agricultural areas of Africa where infant mortality is prevalent and resources are scarce, children's survival and economic future are in jeopardy. Consequently, African parents pursue an investment strategy aimed at physical survival and economical welfare (LeVine, 1980). In the United States, however, parents have vastly different investment strategies and typically emphasize the third level goal of maximizing cultural values. Unlike tropical African societies, American infant mortality rates are low and child labour does not exist, so parents focus more on their children's attainment of position in life and encourage their children to maintain or improve their socioeconomic status (SES) (LeVine, 1980). When asked what their long-term goals were for their children, nearly all American parents in New and Richman's (1996) sample expressed economic and emotional independence. Most parents wanted their children to achieve a sense of well-being and happiness, and the ability to maintain honest and respectful interpersonal relationships. According to LeVine (1980), the goal of independence is embedded in the European-American child-rearing ideology, which consists of separateness, self-sufficiency, and self-confidence. Americans value these qualities of independence, as they represent an ability to cope with a changing environment, to maintain or enhance social status, and to perpetuate the positive affect of early dialogues in later parent-child relations (LeVine, 1980). In sum, 'parental goals are 
aligned with cultural context and are manifested in different socialization strategies' (Bornstein \& Lansford, 2010; p. 261).

\section{Socioeconomic Status}

Although independence and autonomy are generally considered primary goals for American children, American parents' beliefs and goals regarding their children vary as a function of SES. Kohn (1963) found that families from lower SES backgrounds value conformity and obedience (which may be necessary in a more dangerous environment or as a skill for working-class jobs), more than parents from higher SES backgrounds. In regard to developmental outcomes, higher-SES parents give earlier age estimates for children's achievement of developmental milestones (e.g. saying first sound and word) and mastery of culturally valued skills (e.g. manners and toilet training), than parents from lower-SES backgrounds (Hoff, Laursen, \& Tardif, 2002). SES also plays a role in parents' self-efficacy beliefs, as lower-SES parents are less likely to believe they have influence over their child's outcomes than higher-SES parents (Elder, Eccles, Ardelt, \& Lord, 1995), and, as a result less often endorse positive outcomes as child-rearing goals (Hoff et al., 2002).

Also influenced by SES are parent-child verbal interactions. On average, higher-SES parents produce more speech and more complex speech to their children than do lower-SES parents (Hart \& Risley, 1995; Hoff, 2003), and this parental speech is positively related to child language development. These SES differences may be due to differences in parental beliefs. For example, a recent study with American families ranging in SES showed that parental beliefs about child development mediated (i.e. explained) some of the relation between SES and child-directed-speech (Rowe, 2008). Further, more qualitative work has shown extensive social class differences in how parents communicate with children (Bernstein, 1971); differences that directly relate to parental beliefs about their children as communicative partners (Heath, 1983). This link between parental beliefs and talk with children holds even within social classes. For example, one study found a relation between middle-class parents' questioning strategies with preschoolers and their beliefs about the role of the environment in child development (Donahue, Pearl, \& Herzog, 1997). Thus, in broad terms, research supports a relation between parents' child-rearing beliefs and goals and their communicative behaviours with children.

\section{The Present Study}

Goals are of interest for study because they are expected to influence parents' actions (Goodnow \& Collins, 1990). This paper investigates relations between parents' shortand long-term goals for their toddlers and the topics of conversation that parents engage in with their children. We examined this broad question by interviewing parents about their goals and then separately videotaping naturalistic interactions between parents and children. Parent interviews were transcribed and coded for categories of short- and long-term goals, and parent-child interactions were transcribed and coded for topic of parental utterances. This approach allowed us to better understand (1) the types of short- and long-term goals parents have for their toddlers, (2) what parents talk about with their toddlers, (3) whether goals or topics of conversation differ by background factors that vary in the sample (e.g. SES and child gender), and (4) whether there are relations between goals and topics of conversation, controlling for background factors. 


\section{METHOD}

\section{Participants}

Forty-seven toddlers and their primary caregivers participated in the study. The parent-child dyads were drawn from a larger sample of 63 families participating in a longitudinal study of children's language development in the greater Chicago area. Recruitment was based on direct mailings to families in targeted zip codes and an advertisement in a free monthly parenting magazine. Parents who responded participated in a screening questionnaire over the phone during which information was gathered on ethnicity, income, education, language(s) spoken in the home, and child gender. Sixty-three English-speaking families were selected to match as closely as possible the 2000 census data on family income and ethnicity in the greater Chicago area. The criteria for drawing the sample used in the present study were the following. First, 8 of the 63 families were eliminated because in those families both parents shared the primary caregiving role and thus both parents interacted with the child in triadic interaction during data collection. These families were excluded, as the interactions were not considered comparable to the other dyadic interactions. Second, of the remaining 55 primary caregivers, 47 agreed to participate in an additional interview at child age 30 months where detailed parent measures were collected. The 8 primary caregivers who opted not to participate did so for various reasons (e.g. 3 due to the birth of another child, 2 indicated they were too busy, and 3 were not interested or could not be reached).

The final sample for the present study includes 47 primary caregiver-child dyads. One of the primary caregivers is a father and the rest are mothers. ${ }^{1}$ All parents spoke English in the home as the primary language. Thirty-four of the parents are White, five are Black, five are Hispanic, and three are Asian. Nineteen of the children are girls. The families varied in SES. Specifically, the education level of the primary caregiver averaged 16 years of education, equivalent to a college degree (S.D. $=2.09)$ with a range from 10 to 18 years. The average family income was $\$ 62889$ (S.D. $=\$ 30507$ ) with a range spanning from less than $\$ 15000$ a year to over $\$ 100000$. Education and income were positively related to one another $(r=0.36, p<0.05)$. Finally, in this sample, SES and ethnicity were very confounded with the White families being of higher SES on average than the Black or Hispanic families. Thus, in our analyses we use SES as a primary background measure, rather than race/ethnicity.

\section{Parental Interview Procedure}

At child age of 30 months (2.5 years) all parents were interviewed by the first author. Parents' short- and long-terms goals for their children, as well as their parenting experiences were examined using semi-structured, open-ended interviews. Parents were first asked to provide a narrative of a typical day in their child's life, they were asked how much time their child spends watching television and reading books, they were asked what their favourite and least favourite things are about parenting, and they were asked the two questions reported on here: (1) Is there anything in particular you are trying to teach your child right now? And (2) Do you have any specific goals or hopes for your child's future? The first question was designed to elicit short-term goals, and the second question long-term goals. All parents responded to the questions. If the parents mentioned a long-term goal first, they were then asked about short-term goals 
and vice-versa. When finished parents were asked 'anything else?' as a final probe. The parent interviews were audiotaped and transcribed verbatim using the CHAT transcription conventions of the CHILDES system (MacWhinney, 2000). The answers to these final two questions in the parent interviews were then further coded as described below.

\section{Parent Interview Coding}

The transcripts of the parent responses to the questions were coded by a research assistant who was blind to the parents' identity. Employing the first major step in grounded theory, the transcripts of parent interviews were thematically open coded to uncover, name, and develop concepts (Strauss \& Corbin, 1998). Through repeated readings of the transcripts, data were conceptualized or broken down into discrete ideas, and were given labels that represented common patterns regarding short-term and long-term goals. The process of comparative analysis allowed for similar responses that shared common characteristics and related meanings to be classified, or grouped together under particular headings, into distinct categories. For example, parents' long-term goals were classified into ten different categories (i.e. education, career, happy, social-emotional, extracurricular/cultural, family, healthy, religion, negative/avoidance goals, and none), with each having specific examples (e.g. attends college) pertaining to the general heading (e.g. education) (see Table 1 for a description of all the short- and longterm goal categories and examples).

Each parents' response were initially coded in response to the two questions about goals (i.e. short term and long term), and then further coded according to the category (e.g. academic, social-emotional, pragmatic, etc. [short-term] e.g. education, career, happy, etc. [long-term];) in which each response fit. The parents were not limited in the number of goals they could mention. For instance when asked what goals or hopes she had for her toddler, a parent mentioned that she wanted her child to become a lawyer, to be happy, and live a healthy life. All three goals were counted as long-term goals and then each individual goal was further placed into the 'career', 'happy', and 'healthy' categories. When asked whether she was teaching anything in particular to her child, a mother stated she was attempting to toilet-train her son and teaching him the alphabet. Both of these goals were distinguished as short-term goals, but the toilet-training was further coded as 'pragmatic' and the teaching of the alphabet was placed in 'academic' category. For short-term and long-term goals we did not give parents credit for mentioning more than one goal in each category. Thus, a parent was counted as mentioning long-term educational goals if she/he mentioned at least one goal in that category.

Certainly, most parents mentioned multiple short- and long-term goals for their children, and their responses to the interview questions varied from short statements (e.g. 'I just want my child to be happy') to long, detailed descriptions of what they were currently teaching their child and how they wanted them to turn out as adults. Throughout the lengthy answers, the coder reviewed the transcript to decipher each and every long-term and short-term goal that was mentioned. In the case that a parent explained multiple ways in which they wanted their child to excel academically (e.g. wants child to get good grades and go to college), the goal was coded one single time. Thus, all goals that were mentioned by parents were accounted for, but not multiple times within each category. Although it was common for parents who expressed educational longterm goals (e.g. go to college) to also express academic short-term goals (e.g. learn 


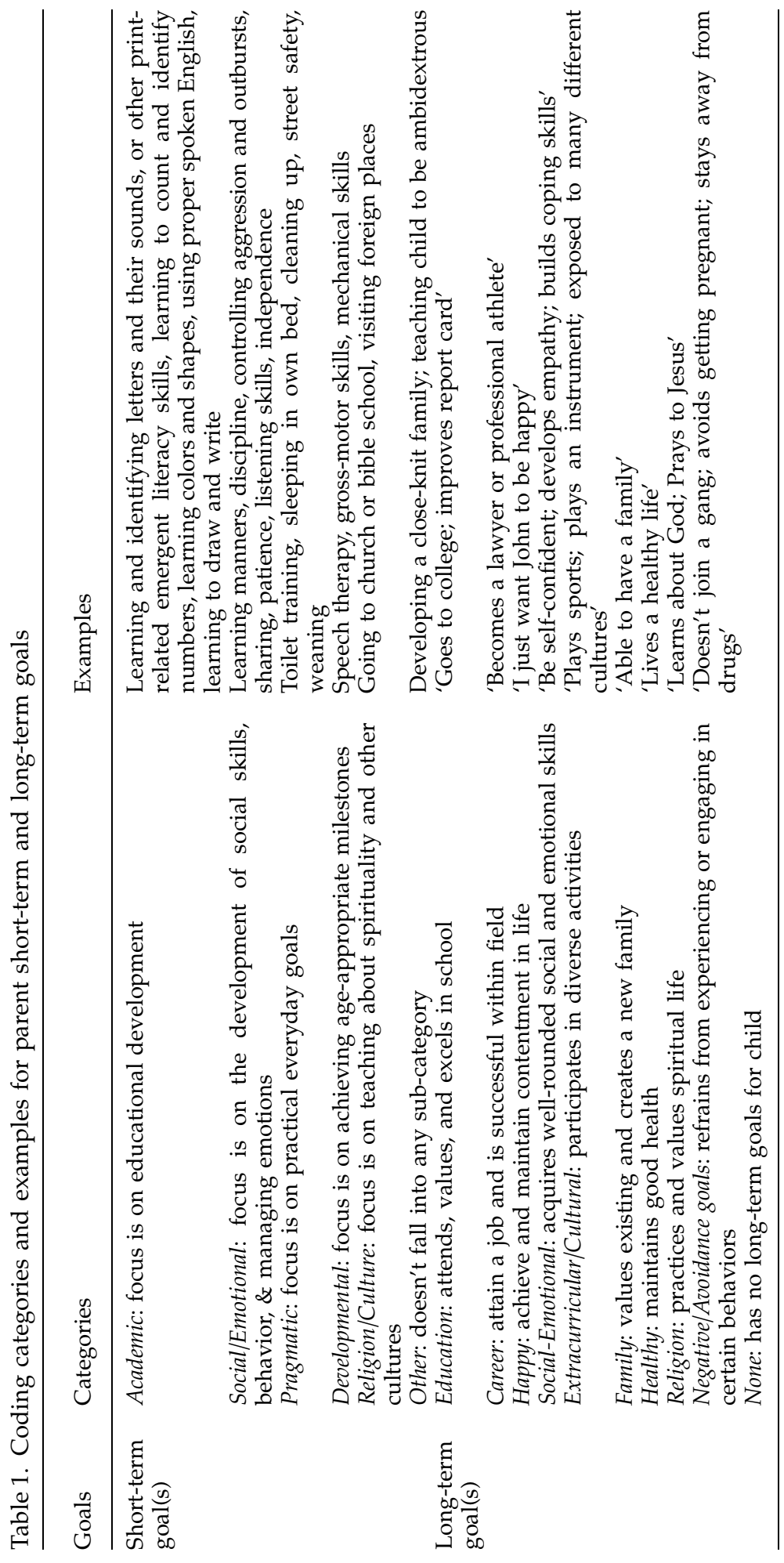


how to count, identify colors), not all parents' long- and short-term goals for their toddlers were related. For example, of the 20 parents who mentioned short-term academic goals, 9 also mentioned long-term educational goals, and of the 26 parents who mentioned short-term social-emotional goals, 8 mentioned longterm social-emotional goals. However, if parents mentioned both educational long-term goals and academic short-term goals, both types of goals were accounted for and coded one time within each category. See Table 1 for an explanation of each category.

Once the short-term and long-term goal categories were developed, there was no ambiguity as to which goal fell into which category. That is, an independent coder categorized $15 \%$ of the goals mentioned and there were no disagreements. There were some goals that did not fall into the categories chosen and thus these were grouped as 'other' (Table 1). The categories were then entered into the transcripts following each utterance that corresponded to a goal and automated analyses of transcripts allowed us to summarize the short-term and long-term goals mentioned by each parent. The coding of all parent interview transcripts was completed prior to coding of the parent-child communicative interactions.

\section{Parent-Child Communicative Interaction Procedure}

Also at child age of 30 months, parent-child dyads were visited in the home and were videotaped engaging in their ordinary daily activities for 90 minutes. These visits occurred, on average, within 5 days of the parent interview. Parents were told to interact as they normally would. The most common types of activities included playing with toys, reading books, and eating meals or snacks. All parent and child speech in the videotaped sessions was transcribed. In transcription, the transcribers were liberal in what counted as a word. All dictionary words, as well as onomatopoeic sounds (e.g. woof-woof) and evaluative sounds (e.g. woops, uh-oh), were counted as words and transcribed. The unit of transcription was the utterance, defined as any sequence of words that is preceded and followed by a pause, a change in conversational turn, or a change in intonational pattern. One rule of thumb transcribers used to determine utterance boundaries was if they perceived punctuation. That is, if a parent is talking and you feel a comma or period should be inserted, then that would be the end of an utterance. For example, 'Don't eat with your fingers, use your fork' would be transcribed as two utterances. Transcription reliability was established at the level of the utterance by having a second individual transcribe $20 \%$ of the videotapes with a reliability criterion of $95 \%$. That is, the two transcribers had to be in agreement on $95 \%$ of the utterances. All parent utterances in the transcripts were then coded for the topic of conversation engaged in as described below. The same research assistant who coded the parent interview coded the parent-child communicative interactions as described below. As noted above, the coder was blind to the parent identity in coding the parent interviews. With the parent-child interactions that was impossible, as the coder needed to watch the videos and insert codes into the transcripts along the way. However, the coder was never aware of which parent interview corresponded to which videotaped parent-child interaction.

\section{Parent-Child Communicative Interaction Coding}

The parent-child videotaped interactions were thematically open coded at the level of the utterance to reveal, identify, and develop concepts, as found in the grounded theory technique (Strauss \& Corbin, 1998). After repeated readings of 
the transcribed conversations, the utterances were conceptualized and initially given labels that broadly related to the short- and long-term goal categories found in the parent interviews (i.e. academic, social-emotional, pragmatic). Also found in the data were patterns of dialogue about playing and watching television, which were each given distinct labels. The coding was explicitly focused on the topic of conversation, not necessarily the activity engaged in. Often the conversational topic and activity were congruent (e.g. watching television and talking about television). However, this was not always the case. For example, parents engaged in academic talk while watching television and engaged in social-emotional talk while eating snacks. Every parent utterance within the interaction was coded according to the five general headings (i.e. social-emotional, academic, pragmatic, play, television), and if any utterance was a conversational filler (e.g. 'umm'), unintelligible, or reactive to the camera, it was coded as 'other'. See Table 2 for these coding categories and examples.

Once the coding system was established to identify topics of conversation during parent-child communicative interactions, a second coder coded $15 \%$ of

Table 2. Coding categories and examples for topic of parent utterances during parentchild interaction

\begin{tabular}{l}
$\begin{array}{l}\text { Topic } \\
\text { category }\end{array}$ \\
\hline
\end{tabular}

Social- Interaction involves parent modeling, Saying 'I'm sorry;' asking child to say emotional eliciting, teaching, explaining, or gener- please or to share; explaining to child 'it's ally talking about how the child should not nice to hit;' asking child if s/he is behave, use manners, or share. Any mad; requesting a hug from child; saying discussion regarding emotions, affection, 'good job' or general praise

Academic Interaction involves parent modeling, Pronouncing words to child; naming eliciting, teaching, explaining, or gener- colors; asking child to identify letters; ally talking about academic information 'what comes after four?;' 'C is for crane;' that is developmentally appropriate for 'just like a dog has a tail, little pigs have toddlers. Academic engagement can take tails;' 'let's count'

place during play and while watching

television, and also includes reading

Pragmatic Interaction involves parent modeling, Showing child how to clean; asking child eliciting, teaching, explaining, or gener- to turn off lights; explaining to child the ally talking about practical, everyday importance of street safety; asking child activities, plans, logistics, or necessary what s/he wants to eat, drink, or do for daily events that must get completed the day; assisting child in using the toilet; 'I'm going to cook lunch'

Play Interaction involves parent talking about 'Do you want to go play trains?;' 'what playing or actual engagement in playing do you want to play with?;' hide and go with toys, games, puzzles, computers, as seek; riding a bike; explaining the rules of well as singing, dancing, coloring/draw- a board game; teaching how to blow ing, and looking through photo albums. bubbles

Also includes parent teaching or explain-

ing how to play with or use toys

Television Interaction involves parent talking about 'Thomas the train is on TV!;' 'Do you or engaging child in watching television want to watch Dora?'

Other Any reactivity to the camera or any talk 'Are you smiling into the camera?;' direct regarding researcher or non-related people. conversations with the researcher; 'huh;' Also includes utterances that are not 'hmm;' 'oops'

intelligible or are conversational fillers 
the transcripts (seven transcripts) for reliability. The percent agreement across the two coders averaged $84.3 \%$. Cohen's kappa was calculated to correct for agreement based on chance and kappa values were good, averaging $79.3 \%$.

\section{RESULTS}

\section{Parent Interview Responses}

Short-term goals

In regard to short-term goals (i.e. what parents were currently teaching their children), more than half of the parents (26 of 47) mentioned socio-emotional skills such as manners and sharing. Twenty of the forty-seven parents explained that they were teaching their children some form of academic information, including letters, numbers, colors, shapes, or other information related to language and literacy skills, math or science. Twenty parents mentioned more pragmatic skills, primarily potty-training, nine parents mentioned other goals/ activities, including religious activities, having multi-cultural experiences, developing appropriate skills for age in general, and one parent mentioned that it was the school's job to teach the child. Again, parents could mention as many activities as they wanted, and the distribution of parents for each short-term goal category is displayed in Figure 1.

\section{Long-term goals}

Just over half of the parents $(n=25)$ expressed some form of education as a long-term goal for their child. Fifteen parents hoped that their children would develop social-emotional skills or characteristics such as confidence and empathy. Eleven parents mentioned that they wanted their children to 'be happy', and seven mentioned specific careers they hoped their children would pursue (e.g. lawyer, basketball player). The remaining goals mentioned fell into the other categories (i.e. extracurricular, family, healthy, religion, negative, or no goal). Parents could mention as many goals as they wanted and thus the categories were not mutually exclusive. The number of parents (out of 47 total) that mentioned each long-term goal type is displayed in Figure 2.

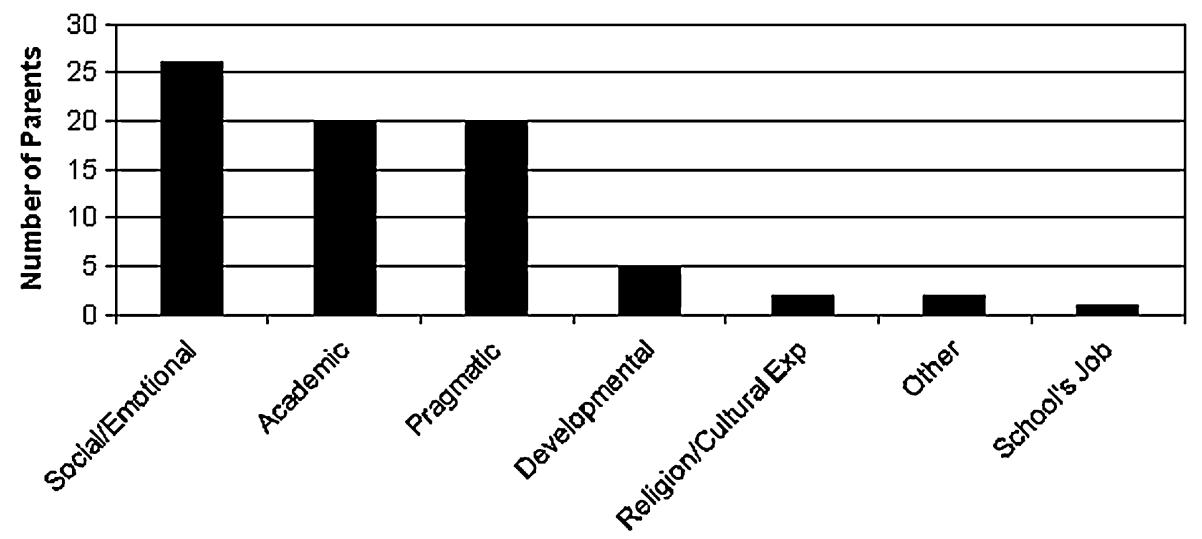

Figure 1. The number of parents (out of 47) mentioning each short-term goal or activity they are trying to teach their child. 


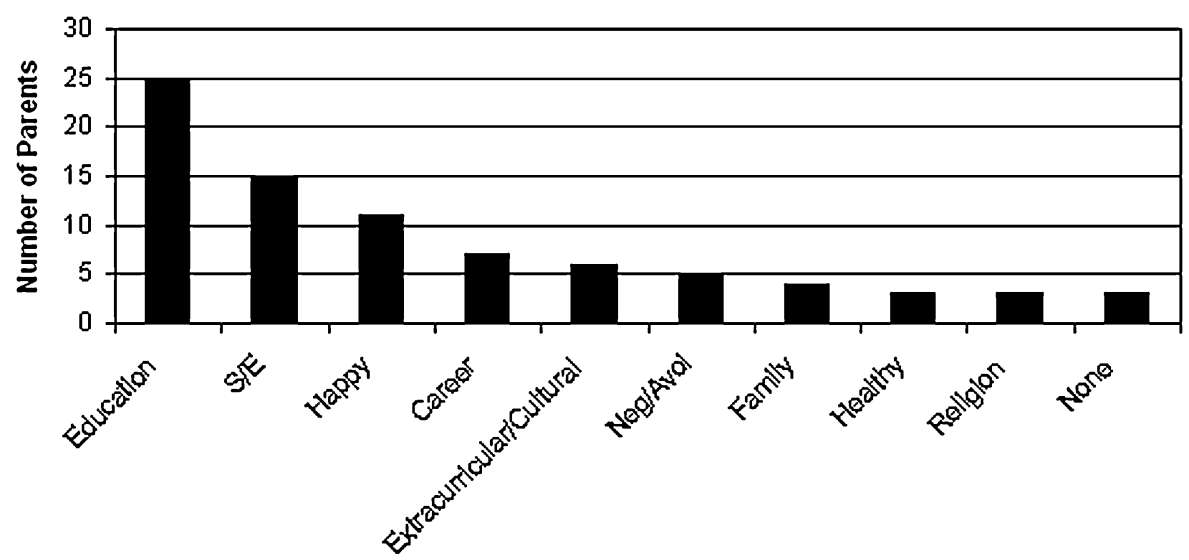

Figure 2. The number of parents (out of 47) mentioning each long-term goal.

To examine potential relations between short- and long-term goals and background factors that varied in the sample (i.e. family income, parent education and child gender) biserial correlation analyses were ran between goals and family income and parent education and chi-square analyses were ran between goals and child gender. Regarding short-term goals, there were no relations between whether or not a parent mentioned at least one academic, socialemotional, or pragmatic goal and child gender or parent education. There was a significant negative relation $(r=-0.36, p<0.05)$ between family income and whether or not the parent mentioned a short-term academic goal. Thus, parents from families with lower annual incomes were more likely to mention short-term academic goals such as working on letters or numbers with children. Income was not related to social-emotional or pragmatic goals. The analyses of long-term goals and background factors resulted in no significant relations between family income, parent education or child gender and type of long-term goal mentioned.

\section{Parent-Child Communicative Interactions}

Parents averaged 897 utterances (range 246-1858) in the 90-minute interaction with their toddlers. On average, the majority of these utterances $(37 \%)$ were focused on pragmatic topics (S.D. $=2.5 \%$ ). Twenty-two percent of the parent utterances were focused on play (S.D. $=2.0 \%), 17 \%$ were about academic topics $($ S.D. $=1.7 \%), 5 \%$ were about social-emotional topics (S.D. $=2.5 \%$ ), just over $1 \%$ focused on television (S.D. $=3.0 \%$ ), and approximately $18 \%$ of utterances were coded as 'other' (S.D. $=13.0 \%$ ) because they were too meaningless to code in the other categories (e.g. oops, hmm). This average breakdown of parent utterances by category is displayed in Figure 3.

There was substantial variation across parents in the amount and topics of their utterances. The overall number of parent utterances was positively related to family income $(r=0.30, p<0.05)$ and more marginally related to parent education $(r=0.24, p=0.10)$. The number of utterances was not related to child gender. Family income was negatively related to the proportion of utterances that were on pragmatic topics $(r=-0.37, p=0.01)$. Parent education was negatively related to the proportion of utterances, which were about television viewing ${ }^{2}$ $(r=-0.37, p=0.01)$ and positively related to the proportion of utterances about 


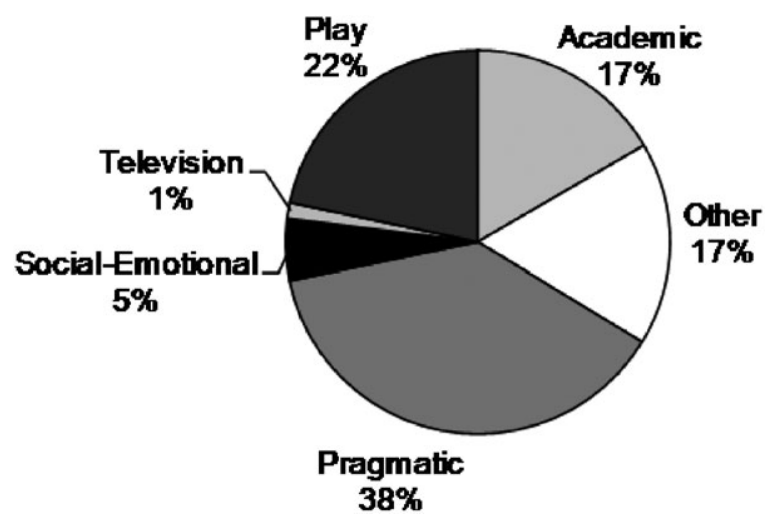

Figure 3. The percentage of parent utterances falling into each topic category.

play $(r=0.31, p<0.05)$. There was no relation between child gender and the proportion of utterances falling into any of the categories. Thus, as with parents' goals, the topics of conversation were evenly distributed across boys and girls.

\section{Relation Between Parental Goals and Topics of Conversations with Children}

To examine relations between parents' short- and long-term goals for their toddlers and the topics of conversation they engage in with their toddlers, biserial correlation analyses were first ran examining relations between goals and talk. The four primary areas of talk included: Pragmatic, academic, social-emotional, and play. ${ }^{3}$ There were no significant relations between short-term goals and parental topics of conversation with children, yet some interesting relations between parents' long-term goals arose, particularly educational goals, and their topics of conversation with children. Specifically, parents who mentioned at least one long-term educational goal for their children $(n=25$, just over half of the sample) devoted more of their talk with children to academic topics $(r=0.29$, $p=0.05)$, marginally more of their talk to play $(r=0.25, p<0.10)$, and less of their talk to pragmatic issues $(r=-0.38, p<0.01)$ than parents who did not mention a long-term educational goal. Follow-up t-tests comparing parents who did and did not mention at least one long-term educational goal on utterance topics revealed some interesting mean differences. Specifically, parents who mentioned educational goals devoted $20 \%$ of their utterances to academic topics, $25 \%$ to play and $32 \%$ to pragmatic topics on average, compared with $13 \%$ for academic topics, $18 \%$ for play and $45 \%$ for pragmatic topics on average for parents who did not mention educational goals. These relations are shown in Figure 4.

We were interested in determining whether the above relations between longterm educational goals and specific topics of conversation would hold when controlling for background factors. Thus, we next ran separate multiple regression analyses predicting variation in topics of conversation (e.g. pragmatic, academic, play) by goals, controlling for family income and parent education. Child gender was not controlled because, as mentioned above, it did not relate to goals or topics of conversation. Family income and parent education were positively related to one another $(r=0.36, p<0.05)$, thus to eliminate possibilities of collinearity and to facilitate the incorporation of interaction variables in the 


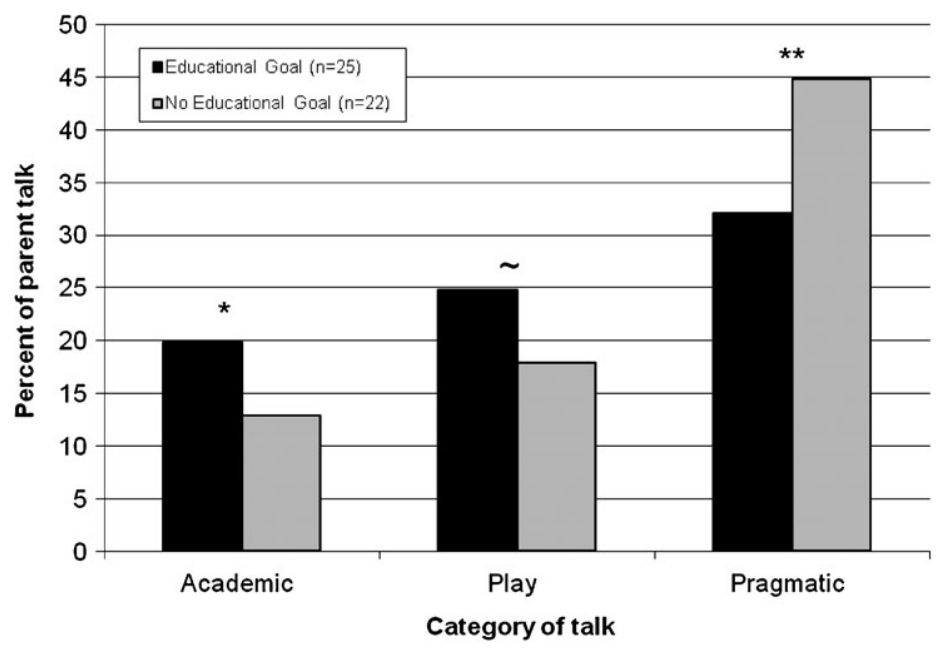

Figure 4. Average proportion of utterances on academic, play, and pragmatic topics for parents who did versus did not mention long-term educational goals.

models we included the SES variable that related most to the topic of conversation being analysed. Family income related to pragmatic talk, parent education related to talk about play, and neither related to academic talk. For academic talk we include education as a control, yet the pattern of results were the same if income was controlled instead. Our goal with the regression analyses was to determine whether goals relate to talk, controlling for SES and whether the effects of goals on talk differ by SES. The correlations were used as a guide to the multiple regression model building. Thus, we considered pragmatic, academic, and play topics of conversation as individual outcome measures. ${ }^{4}$ We then included the SES control variable followed by long-term educational goals (as it was the only goal related to our topic of conversation measures). We also included an interaction term between educational goals and the SES control. However, none of the models resulted in a significant interaction between educational goals and SES, so those models are not presented here. The final results of the regression analyses for each type of talk are presented in Table 3 . All assumptions were met for regression models.

As shown in Table 3, controlling for SES, there was a significant negative relation between long-term educational goals and proportion of talk about pragmatic issues $(p<0.05)$. Further, SES, in this case family income, was also a significant negative predictor of pragmatic talk, controlling for long-term educational goals. There was no interaction between SES and educational goals (not shown), thus the effect of long-term goals on pragmatic talk does not differ by SES. This model containing family income and long-term educational goals explains approximately $22 \%$ of the variation in the proportion of talk about pragmatic topics $(F=6.32, p<0.004)$. Thus, parents who earned higher annual incomes and who have long-term educational goals for their children, devoted less of their talk with their toddlers to pragmatic topics, compared with lower-income parents and parents who did not mention long-term educational goals.

The second column of Table 3 shows the final model predicting the proportion of talk about academic topics. Controlling for SES, educational goals were 
Table 3. Results of multiple regression analyses predicting proportion of talk about pragmatic, academic and play topics based on SES and long-term educational goals $(n=47)$

Topic of conversation

\begin{tabular}{lccc} 
& & & \\
& Pragmatic play $\beta$ (S.E.) & Academic $\beta$ (S.E.) & Play $\beta$ (S.E.) \\
\hline Intercept & 0.54 & 0.25 & -0.10 \\
& $(0.05)$ & $(0.14)$ & $(0.16)$ \\
SES & $-0.002^{*}$ & 0.00 & $0.02^{\sim}$ \\
& $(0.001)$ & $(0.01)$ & $(0.01)$ \\
Educational goal & $-0.102^{*}$ & $0.08^{*}$ & 0.05 \\
& $(0.05)$ & $(0.04)$ & $(0.04)$ \\
R-square statistic $(\%)$ & 22.3 & 9.60 & 12.7 \\
\hline
\end{tabular}

$\sim p<0.10 ;{ }^{*} p \leqslant 0.05$.

Note: family income is the SES measure in the model predicting pragmatic talk, and parent education is the SES measure in models predicting academic talk and play talk.

significantly, positively related to academic talk $(p<0.05)$. There was no interaction between educational goals and SES (not shown) and this model explains $9.6 \%$ of the variation in proportion of talk about academic topics $(F=2.35$, $p=0.10)$. Thus, controlling for SES, parents who mentioned long-term educational goals devoted more of their talk to their toddlers to academic topics than parents who did not mention long-term educational goals.

The final column presents the results of the regression model predicting the proportion of talk about play. Here, SES (e.g. parent education) was a marginally significant $(p<0.10)$ positive predictor of the proportion of talk about play controlling for educational goals, but educational goals was no longer a predictor now that SES was controlled. Thus, the correlation found earlier between educational goals and proportion of talk about play appears to be accounted for by parent education. In this model, SES and educational goals combine to explain $12.7 \%$ of the variation in talk about play $(F=3.21, p=0.05)$. Thus, controlling for whether or not a parent mentioned a long-term educational goal, parents with more education tended to devote more of their talk with their toddlers about topics of play, than parents with less education.

\section{DISCUSSION}

The results of the current study add to our understanding of the relation between parental beliefs and practices by illustrating the relations between parents' longterm goals for their toddlers and the topics of conversation they engage in with their toddlers on a day-to-day basis. We found that the parents in our sample expressed a variety of short- and long-term goals for their toddlers, with the most common goals being focused on educational achievements or social-emotional development. Parents talk to their toddlers about a wide variety of topics, with the majority of their talk focused on pragmatic issues, followed by talk about play and academic talk. In sum, the findings suggest that what parents talk about when they interact with their toddlers relates to their goals for their children (particularly long-term goals about educational attainment) as well as background factors. Just over half of the parents $(n=25)$ expressed their desire for 
their children to obtain and/or excel in their education. Our findings showed that controlling for socio-economic status, parents who expressed long-term educational goals spent more time speaking to their children about academic topics and less time speaking about pragmatic issues, compared with parents who did not mention educational goals.

\section{Relationship Between Educational Goals and Academic Talk}

A great deal of research has supported the existence of a relationship between parental beliefs and goals and parent-child interactions. Specifically, parents' beliefs are considered to help generate and shape parental behaviours, especially in terms of observable interactions with their children (Bornstein \& Cheah, 2006; Johnston \& Wong, 2002). In particular, child-rearing goals are operationalized as the most wanted qualities and characteristics of personality and behaviour that parents attempt to develop in their own children (Cheah \& Chirkov, 2008). Parental goals for children, too, have direct and indirect effects on the outcomes of not only their children's cognitive, emotional, and social competences, but also on the parent-child interactions (Cheah \& Chirkov, 2008). Therefore, it is not surprising that the parents who mentioned educational goals for their children talked more frequently about academic topics with their children, compared with the parents who did not mention educational goals. The congruence between parents expressing educational goals and talking about and engaging in academic topics and activities underscores the relationship between parents' beliefs and parent-child interactions. Parents who actively expressed their desire for their children to excel in education (e.g. 'be a good student', 'go to college') devoted more of their talk to academic topics (e.g. identifying letters, numbers, colors, shapes, to child; pronouncing words to child) than parents who did not mention these educational goals.

What is particularly interesting is that the strongest relations were found between parents' long-term goals and their talk to children. Perhaps this indicates that short-term goals are more transient, whereas long-term goals might be a better measure of parents' belief systems in general. It is clear that parents' belief systems have multiple dimensions (Bond \& Burns, 2006); what is important to recognize is that parental beliefs are relevant to parenting practices and may function as guides for how parents interact with their children. In the current study we cannot claim causality, that parent beliefs are causing them to talk about certain topics; however, our results do in fact show a clear relation between American parents' long-term educational goals for their children and conversations devoted to academic versus pragmatic topics. Ultimately, these results support and extend other findings demonstrating the relationship between parents' beliefs and goals and their subsequent behaviour during their interactions with their children.

\section{Topic of Pragmatics}

It is important to note that pragmatic topics were the most common, on average, across all parental utterances. All parents, regardless of mentioning education goals, devoted a great deal of their talk to pragmatic topics. Pragmatic topics consumed nearly half $(45 \%)$ of talk to children among the parents who did not mention education goals, while pragmatic topics represented almost one-third $(32 \%)$ of talk to children among parents who mentioned education goals. 
On average, parents dedicated $37 \%$ of their aggregate talk to pragmatic topics, indicating that over one-third of the parent-child interactions consisted of talk about practical, daily and necessary events that must be completed. Perhaps this reflects the fact that despite having certain goals for their children, interacting with a toddler in general requires a certain amount of talk about the here-andnow and ongoing events such as changing diapers, eating, and cleaning up. Thus, conversing about pragmatic topics is inevitable, yet what is interesting is the degree to which parents stray from the pragmatic and enter the realm of academic topics of conversation. Indeed parents with education goals spent less of their talk on pragmatic topics than parents who did not mention long-term education goals. It is interesting that controlling for whether or not a parent mentioned a long-term educational goal, family income was negatively related to talk about pragmatics. This suggests that families with lower annual income levels spend more of their utterances on pragmatic topics, than families with higher incomes, regardless of whether they mention a long-term educational goal. This suggests that the lower-income parents are talking more about the here-and-now and is consistent with other findings showing that higher-SES families use more decontextualized talk, or talk about the non-present, with toddlers (Rowe, in preparation).

\section{Topic of Play}

Another distinction between the parents who mentioned educational goals compared with the parents who did not is the amount of talk dedicated to play. Parents who mentioned education goals spoke about play marginally more often than parents who did not mention educational goals. However, this relation did not hold once socio-economic status (parent education) was controlled. That is, SES was driving the relation between educational goals and talk about play. The amount of talk dedicated to play by parents of higher education is noteworthy and suggests that these parents might view play as a useful activity for their children's development. Tamis-LeMonda, Uzgiris, \& Bornstein (2002) acknowledged that parent-child play is considered a meaningful context for social, emotional, communicative, and cognitive development for children. In particular, play allows for children to display their emotional expressivity (Beckwith, 1986; Singer, 1995), for children to learn socially appropriate communication skills, social conduct rules, and culturally appropriate norms (Tamis-LeMonda et al., 2002), for children to develop a sense of efficacy and mastery motivation, and for children to explore creatively, foster divergent and imaginary thinking, and develop problem-solving skills and symbolic functions. Perhaps in Western cultures, parents of different SES hold different views about the importance of play in their children's development.

\section{The Role of SES}

Consistent with results from previous studies (Hart \& Risley, 1995; Hoff-Ginsberg, 1992), we found that parents with higher incomes and more education addressed more speech overall to their children, compared with their counterparts.

The topics of conversation during parent-child interactions also differed as a function of SES. Specifically, higher-SES parents talked more about play and less about pragmatic topics and television than lower-SES parents, while lower-SES parents tended to devote a higher proportion of their talk to television and 
pragmatic subjects and less talk to play. These results are not surprising, as higher-SES parents are found to hold stronger self-efficacy beliefs in terms of their role in helping their children achieve developmental and educational outcomes and are found to have higher expectations for their children in terms of attaining developmental milestones (Hoff et al., 2002).

What is fairly surprising is that we did not find any relation between SES or other background factors and parental long-term goals for children. That is, we see relations here between SES and topics of parental conversations with children, and between parental long-term goals and parental communication with children, but not between SES and parental goals. Perhaps our open-ended measure of parental goals was not sensitive enough to pick up on potential differences in social class (Sigel, 1992). Or, perhaps this sample of American families has goals that are more or less independent from their socioeconomic background. Or, it may be that these American parents from different SES groups do have similar goals, yet different strategies for promoting these goals. Further, the one relation between SES and goals that we did find was a negative relation between family income and parental short-term academic goals. Thus, parents with larger annual incomes were less likely to mention short-term academic goals than parents with smaller incomes. This is somewhat surprising given the aforementioned research that higher SES parents often believe they play a larger role in teaching their children than lower-SES parents. However, it may indicate that the higher income parents are more worried about their toddler's behaviour rather than their cognitive advances at this point in development (e.g. the terrible two's) and thus the question might be eliciting more immediate concerns rather than goals per-se.

\section{Limitations and Implications}

This study was conducted with a relatively small sample of American families and consequently, findings of relations between parental beliefs and talk cannot be generalized to a larger population. Further, the relations found between beliefs and talk were relatively few compared with the number of goals we examined. However, the results suggest an interesting link between parental long-term goals for toddlers and what parents choose to talk about with their children. Thus, parental topics of conversation may be influenced by parents' goals and beliefs as are more general cultural patterns of language use.

The measure of parental topics of conversation in this study was likely confounded with the types of activities parents choose to engage in with their children. That is, much of the talk about play occurred during play, and talk about pragmatic activities occurred during pragmatic activities. However, this was not uniformly the case. For example, talk coded as academic or socialemotional also occurred during play and during pragmatic activities (e.g. snacks, diaper changing). This area of research could be examined further by collecting data in a more structured way (e.g. having all parents engage in the same activities), which would allow one to disentangle the effects of time spent on activity versus topic of conversation. Nonetheless, in this study whether or not topic of conversation is an index of activities engaged in, it does represent the communication the parent offers the child and is a reasonable approach to examining links between goals and communicative behaviour.

Finally, in this study child outcomes were not examined, yet one might consider that these differences in parental topics of conversation with children 
might lead to differences in child development. Parents whose topics of conversation focus primarily on social-emotional factors (e.g. manners, sharing) may have more socially adjusted or polite children (e.g. who more frequently use manners or share). Moreover, those parents who talk, elicit, and model academic information to/from their children perhaps have children with more advanced cognitive skills. Future research should further investigate the links between parental beliefs and goals, parental talk with children, and children's developmental outcomes.

\section{ACKNOWLEDGEMENTS}

This research was supported by grants from the NICHD: F32HD045099 and K99HD055522 to the first author, and P01HD40605 to Susan Goldin-Meadow. We thank the participating parents and children for sharing their lives with us; Nicole Denmark for comments on an earlier version of the paper; K. Brasky, L. Chang, E. Croft, K. Duboc, J. Griffin, S. Gripshover, K. Harden, L. King, C. Meanwell, E. Mellum, M. Nikolas, J. Oberholtzer, C. Rousch, L. Rissman, B. Seibel, M. Simone, K. Uttich, and J. Wallman for help in collecting and transcribing the interaction data; Kristi Schonwald and Jason Voigt for administrative and technical assistance.

\section{Notes}

1. We considered eliminating the father-child dyad from the study because there was only one father primary caregiver. However, he was not an outlier on any measure and thus his goals and interactions did not differ from the mothers' so we decided to include him.

2. Very little talk was about television so this finding should be interpreted cautiously.

3. Talk about television was so infrequent and the distribution was so skewed that we could not consider it further in analyses.

4. The predictors of social-emotional talk were not examined because no goals were correlated with social-emotional talk.

\section{REFERENCES}

Beckwith, L. (1986). Parent-infant interaction and infants' social-emotional development. In A. W. Gottfried, \& C. C. Brown (Eds.), Play interactions (pp. 279-292). Lexington, MA: Heath.

Benasich, A. A., \& Brooks-Gunn, J. (1996). Maternal attitudes and knowledge of childrearing: Associations with family and child outcomes. Child Development, 67, 1186-1205.

Bernstein, B. (1971). Class, codes and control: Theoretical studies towards a sociology of language. New York: Schocken Books.

Bond, L. A., \& Burns, C. E. (2006). Mothers' beliefs about knowledge, child development, and parenting strategies: Expanding the goals of parenting programs. The Journal of Primary Prevention, 27, 555-571.

Bornstein, M. H., \& Cheah, C. S. L. (2006). The place of 'Culture and Parenting' in the ecological contextual perspective on developmental science. In K. H. Rubin, \& O. B. Chung (Eds.), Parenting beliefs, behaviors, and parent-child relations (pp. 3-33). New York: Psychology Press. 
Bornstein, M. H., \& Lansford, J. E. (2010). Parenting. In M. H. Bornstein (Ed.), Handbook of cultural developmental science (pp. 259-277). New York: Taylor \& Francis Group.

Chao, R. (1996). Chinese and European American mothers' beliefs about the role of parenting in children's school success. Journal of Cross-Cultural Psychology, 27, 403-423.

Cheah, C. S. L., \& Chirkov, V. (2008). Parents' personal and cultural beliefs regarding young children. Journal of Cross-Cultural Psychology, 39, 402-423.

Cote, L. R., \& Bornstein, M. H. (2000). Social and didactic parenting behaviors and beliefs among Japanese American and South American mothers of infants. Infancy, 1, 363-374.

Darling, N., \& Steinberg, L. (1993). Parenting style as context: An integrative model. Psychological Bulletin, 113, 487-496.

Donahue, M. L, Pearl, R., \& Herzog, A. (1997). Mothers' referential communication with preschoolers: Effects of children's syntax and mothers' beliefs. Journal of Applied Developmental Psychology, 18, 133-147.

Elder Jr, G. H., Eccles, J. S., Ardelt, M., \& Lord, S. (1995). Inner-city parents under economic pressure: Perspectives on the strategies of parenting. Journal of Marriage and the Family, 57, 771-784.

Gaskins, S. (1996). How Mayan parental theories come into play. In S. Harkness, \& C. M. Super (Eds.), Parents' cultural belief systems: Their origins, expressions, and consequences (pp. 345-363). New York: Guilford.

Goodnow, J. J. (2002). Adding culture to studies of development: Toward changes in procedure and theory. Human Development, 45, 237-245.

Goodnow, J. J., \& Collins, W. A. (1990). Development according to parents: The nature, sources, and consequences of parents' ideas. Hillsdale, NJ: Erlbaum.

Grusec, J. E., Rudy, D., \& Martini, T. (1997). Parenting cognitions and child outcomes: An overview and implications for children's internalization of values. In J. E. Grusec, \& L. Kuczynski (Eds.), Parenting and children's internalization of values: A handbook of contemporary theory (pp. 259-282). Hoboken, NJ: Wiley.

Harkness, S., \& Super, C. M. (Eds.). (1996). Parents' cultural belief systems: Their origins, expressions, and consequences. New York: Guilford.

Hart, B., \& Risley, T. (1995). Meaningful differences in the everyday experience of young American children. Baltimore: Brookes.

Heath, S. B. (1983). Ways with words: Language, life and work in communities and classrooms. Cambridge, England: Cambridge University Press.

Hoff, E. (2003). Causes and consequences of SES-related differences in parent-to-child speech. In M. H. Bornstein, \& R. H. Bradley (Eds.), Socioeconomic status, parenting, and child development (pp. 147-160). Mahwah, NJ: Lawrence Erlbaum Assoc.

Hoff, E., Laursen, B., \& Tardif, T. (2002). Socioeconomic status and parenting. In M. H. Bornstein (Ed.), Handbook of parenting: Vol. 2. Biology and Ecology of Parenting (pp. 231-252). Mahwah, NJ: Erlbaum.

Hoff-Ginsberg, E. (1992). How should frequency in input be measured? First Language, $12,233-245$.

Jimerson, T. L., \& Bond, L. A. (2001). Mothers' epistemologies, turn-taking, and contingent interaction with preschoolers. Applied Developmental Psychology, 22, 379-396.

Johnson, J. R., \& Wong, M. Y. (2002). Cultural differences in beliefs and practices concerning talk to children. Journal of Speech, Language, and Hearing Research, 45, 916-926.

Keller, H., Papaligoura, Z., Kuensemueller, P., Voelker S., Papaeliou, C., Lohaus, A., et al. (2003). Concepts of mother-infant interaction in Greece and Germany. Journal of CrossCultural Psychology, 34, 677-689.

Kohn, M. (1963). Social class and parent-child relationships: An interpretation. The American Journal of Sociology, 68(4), 471-480.

LeVine, R. A. (1974). Parental goals: A cross-cultural view. Teachers College Record, 76, 226-239.

LeVine, R. A. (1980). A cross-cultural perspective on parenting. In M. D. Fantini, \& R. Cardenas (Eds.), Parenting in a multicultural society (pp. 17-26). Boston, MS: Allyn \& Bacon.

LeVine, R. A., Miller, P. M., Richman, A. L., \& LeVine, S. (1996). In S. Harkness, \& C. M. Super (Eds.), Parents' cultural belief systems: Their origins, expressions, and consequences (pp. 251-269). New York: Guilford.

Lieven, E., \& Stoll, S. (2010). Language. In M. H. Bornstein (Ed.), Handbook of cultural developmental science (pp. 143-160). New York: Taylor \& Francis Group. 
Luster, T., \& Okagaki, L. (1993). Multiple influences on parenting: Ecological and lifecourse perspectives. In L. Okagaki (Ed.), Parenting: An ecological perspective (pp 227-250). Hillsdale, NJ: Erlbaum.

Maccoby, E. E., \& Martin, J. A. (1983). Socialization in the context of the family: Parent-child interaction. In M. Hetherington (Ed.), Handbook of child psychology Vol. 10. (pp. 1-103). New York, NY: Wiley.

MacWhinney, B. (2000). The Format and Programs. The CHILDES Project: Tools for analyzing talk (3rd ed., Vol. 1). Mahwah, NJ: Lawrence Erlbaum Associates.

McGillicuddy-De Lisi, A. V. (1992). Parents' beliefs and children's personal-social development. In I. E. Sigel, A. V. McGillicuddy-De Lisi, \& J. J. Goodnow (Eds.), Parental belief systems: The psychological consequences for children (2nd ed., pp. 115-142). Hillsdale, NJ: Lawrence Erlbaum Associates.

McGillicuddy-De Lisi, A. V., \& Sigel, I. E. (1995). Parental beliefs. In M. H. Bornstein (Ed.), Handbook of parenting (pp. 333-358). Mahwah, NJ: Erlbaum.

Miller, S. A. (1988). Parents' beliefs about children's cognitive development. Child Development, 59, 259-285.

New, R. S., \& Richman, A. L. (1996). Maternal beliefs and infant care practices in Italy and the United States. In S. Harkness, \& C. M. Super (Eds.), Parents' cultural belief systems: Their origins, expressions, and consequences (pp. 385-404). New York: Guilford.

Ochs, E. (1988). Culture and language development. New York: Cambridge University Press.

Pomerleau, A., Malcuit, G., \& Sabatier, C. (1991). Child-rearing practices and parental beliefs in three cultural groups of Montreal: Quebecois, Vietnamese, Haitian. In M. H. Bornstein (Ed.), Cultural approaches to parenting (pp. 45-68). Hillsdale, NJ: Erlbaum.

Rogoff, B. (2003). The cultural nature of human development. New York: Oxford University Press.

Rowe, M. L. (2008). Child-directed speech: Relation to socioeconomic status, knowledge of child development, and child vocabulary skill. Journal of Child Language, 35, 185-205.

Rowe, M. L. Parental talk to children: The importance of quantity versus quality in child vocabulary skill; under review.

Schieffelin, B. B. (1990). The give and take of everyday life: The language socialization of Kaluli children. New York: Cambridge University Press.

Sigel, I. (1992). The belief-behavior connection: A resolvable dilemma? In I. Sigel, A. McGillicuddy-Delisi, \& J. Goodnow (Eds.), Parental belief systems: The psychological consequences for children (pp. 433-456). Hillsdale, NJ: Lawrence Erlbaum Associates.

Sigel, I. E., \& McGillicuddy-De Lisi, A. V. (2002). Parent beliefs are cognitions: The dynamic belief systems model. In M. H. Bornstein (Ed.), Handbook of parenting: Vol. 3. Being and becoming a parent (2nd ed., pp. 485-502). Mahwah, NJ: Erlbaum.

Singer, J. L. (1995). Imaginative play in childhood: precursor of subjunctive thought, daydreaming, and adult pretending games. In A. D. Pellegrini (Ed.), The future of play theory (pp. 187-219). Albany: State University of New York Press.

Strauss, A., \& Corbin, J. (1998). Basics of qualitative research: Techniques and procedures for developing grounded theory. Thousand Oaks, CA: Sage.

Tamis-LeMonda, C. S., Uzgiris, I. C., \& Bornstein, M. H. (2002). Play in parent-child interactions. In M. H. Bornstein (Ed.), Handbook of parenting: Vol. 5. Practical Issues in Parenting (pp. 221-241). Mahwah, NJ: Erlbaum.

Teti, D. M., \& Candelaria, M. (2002). Parenting competence. In M. H. Bornstein (Ed.), Handbook of parenting: Vol. 4. Applied parenting (2nd ed., pp. 149-180). Mahwah, NJ: Lawrence Erlbaum.

Wang, S., \& Tamis-LeMonda, C. S. (2003). Do child-rearing values in Taiwan and the United States reflect cultural values of collectivism and individualism? Journal of CrossCultural Psychology, 34, 629-642.

Williams, D., \& Ispa, J. M. (1999). A comparison of the child-rearing goals of Russian and U.S. university students. Journal of Cross-Cultural Psychology, 30, 540-547. 